\title{
ANÁLISE DA PRODUÇÃO CIENTÍFICA DA TEMÁTICA GESTÃO SOCIOAMBIENTAL NA PERSPECTIVA DA REVISTA RGSA
}

\author{
Henrique César Melo Ribeiro \\ Doutorando em Administração pela Uninove \\ hcmribeiro@hotmail.com \\ Rosany Corrêa \\ Doutoranda em Administração pela Uninove \\ rosanycorrea@hotmail.com
}

\begin{abstract}
RESUMO
Este artigo investigou a produção científica da temática gestão socioambiental publicada pela Revista de Gestão Social e Ambiental, no período de 2007 a 2012. Este estudo se baseia numa pesquisa bibliométrica e sociométrica, utilizando-se de estatística descritiva em 175 artigos identificados. Os principais resultados foram os seguintes: 90,86\% dos artigos foram publicados em parceria; UFRGS, USP, UFBA e Uninove foram as IESs que mais publicaram, sendo também, consequentemente, as instituições mais centrais e que estão entre as $11 \mathrm{IESs}$ com maior número de autores vinculados; ética e responsabilidade social, contabilidade ambiental, marketing verde, gestão ambiental em setores específicos e os indicadores de sustentabilidade foram os temas considerados de fronteira nessas pesquisas.
\end{abstract}

Palavras-chave: Bibliometria; Gestão ambiental; Gestão social; Sociometria.

\section{ANALYSIS OF SCIENTIFIC PRODUCTION OF ENVIRONMENTAL MANAGEMENT IN THE PERSPECTIVE ISSUE OF THE JOURNAL OF SOCIAL AND ENVIRONMENTAL MANAGEMENT (RGSA)}

\begin{abstract}
This paper investigated the scientific theme of environmental management published by the Journal of Social and Environmental Management (RGSA), in the period 2007-2012. This study is based on bibliometric and sociometric research, using descriptive statistics in 175 identified articles. The main results were as follows: $90.86 \%$ of the articles were published in partnership; the Federal University of Rio Grande do Sul (UFRGS), the Universtity of São Paulo (USP), the Federal University of Bahia (UFBA), and Nove de Julho University (Uninove) were the Higher Education Institutions (HEIs) that published most. Consequently, these are the most important HEIs, which are among the 11 HEIs with the highest number of authors in this field; ethics and social responsibility, environmental accounting, green marketing, environmental management in specific sectors, and indicators of sustainability were the topics considered in this research area.
\end{abstract}

Key words: Bibliometrics; Environmental management; Social management; Sociometry. 


\section{INTRODUÇÃO}

As últimas duas décadas têm apresentado avanço no desenvolvimento de técnicas de mensuração e evidenciação de informações de caráter ambiental (Rover, Santos \& Salotti, 2012), podendo ser em razão da grande evolução de pesquisas científicas (Moura et al., 2012). Neste aspecto, a produção científica nacional vem evoluindo nos últimos anos, sendo consolidada por meio de pesquisadores e evidenciada mediante periódicos acadêmicos. Tais revistas são preponderantes para este crescimento, pois socializam ensaios, resenhas, casos de ensino e artigos.

Entre as revistas brasileiras com classificação no sistema Qualis/Capes e que têm linha editorial sobre temas ligados às áreas de política e gestão socioambiental, encontra-se a Revista de Gestão Social e Ambiental - RGSA, que no último triênio Capes (2010/2012), teve conceito B2 (Capes, 2012). O sítio eletrônico da revista destaca que a RGSA é uma publicação de caráter científico, que visa ampliar a discussão e disseminação da temática socioambiental, resultante de pesquisas acadêmicas (RGSA, 2012).

Diante do exposto, ressalta-se a questão de pesquisa que norteou este trabalho: qual o perfil da produção científica brasileira sobre a temática gestão socioambiental, na perspectiva da revista RGSA? O objetivo dessa pesquisa foi investigar a produção científica brasileira da temática gestão socioambiental, por meio dos seguintes indicadores: (I) número de autores por publicação; (II) autores mais prolíferos; (III) redes de coautoria; (IV) IESs mais profícuas; (V) rede das IESs; (VI) rede integrada dos autores e IES; (VII) autores e obras mais citadas; (VIII) frequência de palavraschave; e (IX) áreas temáticas e temas abordados.

Este artigo está organizado em cinco partes. A primeira, contempla a introdução, com a justificativa, questão e o objetivo da pesquisa. O referencial teórico é evidenciado na parte dois, gestão socioambiental e responsabilidade socioambiental. Depois, são expostos os procedimentos metodológicos usados na pesquisa. A quarta parte aborda a análise e discussão dos resultados. Por fim vêm as considerações finais, limitações da pesquisa e as recomendações para estudos futuros.

\section{REFERENCIAL TEÓRICO}

Esta seção apresenta algumas abordagens teóricas sobre gestão social e ambiental e as pesquisas bibliométricas e/ou sociométricas sobre gestão socioambiental e temáticas afins.

\subsection{Gestão social e responsabilidade social}

A gestão social deve se ocupar com gestão de políticas sociais. Pode ser entendida como: ações de desenvolvimento local; um processo social (Bordin, 2009); um processo de desenvolvimento (Fischer, 2002), sendo o campo da gestão social o do desenvolvimento social (Pacheco et. al., 2013). Na atualidade, a gestão social passa a ser praticada, não somente atrelada às políticas públicas, mas pode ser incorporada pelas organizações na forma de responsabilidade social.

A responsabilidade social tem evoluído na sociedade (Gómez \& Castillo, 2007) e, consequentemente, nas empresas (Ashley, 2002; Reis, 2007), influenciando os atores sociais a assumirem as melhorias necessárias para que o desenvolvimento social seja considerado cenário econômico (Carroll, 1979). O conceito de responsabilidade social chegou ao conceito de compromisso ético, traduzido pelo Instituto Ethos (2012) como conceito aplicado à gestão dos negócios. Nas empresas, esses valores éticos são percebidos como positivos pela sociedade e tendem a orientar a conduta da organização fundamentada em uma missão social. A responsabilidade social cria valor (Rodriguez, Diniz \& Ferrer, 2007) para os públicos com os quais a empresa se relaciona, entre eles, empregados, fornecedores, governo e a comunidade em geral.

A responsabilidade social empresarial tem sido bastante discutida tanto no meio acadêmico (Moretti \& Campanário, 2009), quanto no empresarial, bem como consideravelmente disseminada pela mídia, com a crescente adoção por parte das organizações e seus reais interesses em tais ações (Paula, Oliveira \& Oliveira, 2010). Zylbersztajn (2000) considera que a adoção de práticas de 
responsabilidade social, mesmo que seja na ótica maximizadora do lucro, sem que a empresa obtenha ganhos econômicos, esta se beneficiará com a elevação do seu capital reputacional e, a rigor, sem desalinhamento de interesses entre acionistas e demais partes interessadas.

Segundo Barbieri (2007), a responsabilidade social é o comprometimento permanente do empresariado em adotar um comportamento ético que contribui para o desenvolvimento financeiro e econômico, integrando o desenvolvimento sustentável nas questões sociais, visando a sustentabilidade (Borger, 2006).

Pereira e Campos Filho (2007) afirmam que, embora o contexto social em que as empresas estão inseridas apresente diversos pontos vulneráveis, em relação aos quais a responsabilidade social corporativa vem demonstrando ser importante, observa-se um grande número de projetos sociais desenvolvidos pelas empresas com foco orientado para o assistencialismo e para a divulgação dessa iniciativa. Já para Melo Neto e Froes (1999), muitas organizações privilegiam, primeiramente, a responsabilidade social direcionada ao público externo em detrimento das ações de responsabilidade social interna, por acreditarem que a primeira traz mais resultados para a imagem da organização.

Toda teoria relativa à temática da responsabilidade social empresarial possui, em si, uma vinculação com as questões de geração de lucro, performance política, demandas sociais e valores éticos, mas abordam esses temas de forma diferenciada e com diferentes pesos (Garriga \& Melé, 2004), isso porque a forma como a empresa atua e desenvolve suas ações sociais está relacionada com sua cultura e estratégias específicas (Macêdo \& Cândido, 2011).

Assim, para Tódero, Macke e Biasuz (2011), existe uma razoável concordância em se afirmar que companhias responsáveis são aquelas que vão além de suas obrigações legais, no tratamento justo de seus empregados; na relação transparente e ética com clientes, fornecedores e concorrentes; na minimização dos danos e impactos ambientais provocados; e no apoio às comunidades locais, e na promoção dos direitos humanos.

\subsection{Gestão ambiental}

É fato que o tema ambiental vem crescendo na literatura acadêmica (Gallon et al., 2007; Pereira et al., 2011; Souza \& Ribeiro, 2013), contudo, as mudanças realizadas nos ambientes das empresas, motivadas por problemas de ordem ambiental, levam as organizações a integrar mecanismos sistêmicos de desenvolvimento sustentável (Sachs, 2002). Além disso, a evolução da temática no meio empresarial torna estas empresas proativas do ponto de vista ambiental e, em alguns casos, aumenta a vantagem competitiva (Porter \& Linde, 1995). A organização que adota uma postura ambiental sistematizada pode alcançar a redução de custos pela eliminação de desperdícios, minimização dos riscos de acidentes ambientais ao identificar vulnerabilidades nos seus processos e produtos (Saggin et. al., 2010).

Um contexto mundial marcado pela degradação e pelo alvitre permanente ao meio ambiente tem imposto uma nova postura das organizações (Jabbour \& Santos, 2006). Para Farias, Góes e Silva Júnior, (2010), o maior desafio, quando se trata de discutir a gestão ambiental empresarial, é de prevenir e controlar os impactos de um empreendimento sobre o meio ambiente e compatibilizar o crescimento econômico com a preservação ambiental, já que quanto menos resíduos as indústrias gerarem, menor será o gasto na produção.

Dessa forma, a gestão ambiental pode ser entendida como o conjunto de procedimentos que visam à conciliação entre desenvolvimento e o ambiente e ocorre por meio da observância da capacidade de suporte do meio ambiente e das necessidades identificadas pela sociedade civil ou pelo governo ou ainda por ambos (Souza, 2000). A gestão global do processo produtivo inclui atividades de planejamento e ação, processos e recursos para desenvolver, implementar, atingir e analisar criticamente, além de manter a política ambiental dentro de uma organização (Saggin et. al., 2010). 
Em suma, a gestão ambiental pode ser entendida como as diretrizes e atividades administrativas e operacionais que têm como objetivo obter efeitos positivos sobre o meio ambiente, sendo que qualquer processo produtivo requer recursos e geram resíduos, de tal forma que a atividade humana já ameaça a capacidade de suporte do planeta (Barbieri, 2007). Os diferentes setores e práticas adotadas pelas organizações produzem diferentes impactos e gerações de dejetos, sendo a gestão ambiental definidora de abordagens que podem ser adotadas pelas empresas para evitar problemas ambientais.

Assim sendo, as empresas precisam adotar novas posturas, implementar novas tecnologias, sistematizar processos, para atender a legislação vigente, com vistas a consolidação do desenvolvimento sustentável por meio da gestão ambiental.

\subsection{Estudos bibliométricos e/ou sociométricos sobre o tema gestão socioambiental e/ou temáticas afins}

Verifica-se que o número de estudos que focam o perfil da produção do tema socioambiental ou correlato, vem apresentando constante crescimento na literatura acadêmica. Sendo assim, é preponderante evidenciar essas pesquisas, para que possam contribuir para o fomento do tema e a discussão dos resultados deste estudo.

Gallon et al. (2007) examinaram as características metodológicas de artigos científicos da área ambiental, durante o período de 2000 a 2006. Os autores constataram similaridade entre os papers publicados no Congresso USP e no EnANPAD, no que tange a abordagem metodológica e quantidade de pesquisadores por estudo. Os temas estão relacionados às seguintes categorias: contabilidade ambiental, evidenciação ambiental, gestão ambiental e sustentabilidade.

Gallon et al. (2008) traçaram um panorama da produção científica em Administração sobre a temática ambiental. Os resultados alcançados pelos autores na análise dos 165 artigos sobre a temática ambiental, publicados nos fóruns da área de Administração, permitem dizer que um aspecto positivo nas publicações da área é o fato de se identificar alguma perspectiva de inserção internacional. Por outro lado, constatou-se, ainda, o uso de livros, produção consolidada, mas que não reflete necessariamente o estado da arte da temática, pelo menos no sentido de processo contínuo de construção de conhecimento.

Nascimento et al. (2009) identificaram e caracterizaram a pesquisa em disclosure social e ambiental. Os autores constataram que os principais centros de pesquisa sobre os temas são: Reino Unido, Austrália, Estados Unidos, Canadá e Nova Zelândia.

Pereira et al. (2011) investigaram a presença do tema sustentabilidade socioambiental nos artigos do International Journal of Operations \& Production Management. Os resultados encontrados pelos autores apontam a evolução do assunto investigado na área de gestão de operações. Concluíram também que as cocitações envolvendo a temática sustentabilidade socioambiental vêm crescendo na área de gestão de operações.

Souza et al. (2011) verificaram as características da produção científica das dissertações e teses que tratam do tema sustentabilidade ambiental em programas stricto senso de administração do Brasil, no período de 1998 à 2009. Os dados mostram uma predominância de teses e dissertações voltadas para os seguintes temas: Gestão Ambiental, Desenvolvimento Sustentável, Sustentabilidade Empresarial, Gestão de Resíduos Sólidos, Turismo Sustentável, Marketing Verde, Recursos Naturais, Sistema de Gestão Ambiental, MDL e Inventário de Emissões e Energias Alternativas, que correspondem a mais de $70 \%$ dos trabalhos da área.

Grzebieluckas, Campos e Selig (2012) analisaram a produção científica sobre contabilidade e custos ambientais no período de 1996 a 2007. No geral, os pesquisadores constataram que a temática custos ambientais ganhou maior atenção por parte dos pesquisadores, representando $61 \%$, contra $39 \%$ dos estudos que abordaram contabilidade ambiental. Verificaram também que, dos 148 autores identificados, 13 deles foram responsáveis por 48,75\% do total das publicações. 
Sehnem et al. (2012) identificaram a evolução do interesse de publicação da administração nas questões da gestão ambiental, estratégia ambiental, do desempenho ambiental e da avaliação estratégica ambiental, mediante a verificação de artigos com estas temáticas em periódicos da área. Constataram que os anos de maior publicação dos artigos foram 2006 e 2009. Os autores que mais publicaram tiveram participação em sete artigos. Concluíram que a temática ambiental recebe atenção da academia brasileira, inclusive com edições especiais para discutir o assunto.

Trierweiller et al. (2012) analisaram a publicação sobre "gestão ambiental" em revistas brasileiras da área de engenharia de produção. Os autores perceberam a tendência em estudos para mensurar o desempenho ambiental das empresas; contudo, as metodologias de avaliação e a definição e utilização de indicadores ou índices necessitam de aprimoramento.

Machado Júnior et al. (2013) verificaram as características da produção científica dos artigos sobre o tema sustentabilidade ambiental no Simpósio de Administração da Produção, Logística e Operações Internacionais - Simpoi, de 1998 a 2011. Observaram que os artigos voltados para a cadeia de suprimentos verdes, sustentabilidade empresarial, gestão ambiental, desenvolvimento sustentável e sistema de gestão ambiental se mostraram predominantes em relação às demais categorias de temas tratados pela sustentabilidade ambiental.

Souza e Ribeiro (2013) investigaram o perfil das pesquisas e a evolução do tema sustentabilidade ambiental nos artigos publicados em periódicos nacionais Qualis de Administração de A1 a B2, no período de 1992 a 2011. Os resultados observados pelos pesquisadores, mostraram que há alguns indícios que favorecem tanto a qualidade quanto a consolidação da pesquisa em sustentabilidade ambiental no Brasil.

Em suma, foram encontrados vários estudos bibliométricos sobre gestão ambiental e social, particularmente em congressos e periódicos científicos nacionais e internacionais. No entanto, não foram identificadas pesquisas sociométricas e bibliométricas sobre a revista RGSA, que trata especificamente do tema socioambiental.

\section{PROCEDIMENTOS METODOLÓGICOS}

Sabe-se que a produção científica é um dos elementos de maior importância no conjunto das atividades acadêmicas, dado que, por meio dela, o conhecimento desenvolvido no âmbito das Instituições de Ensino Superior é difundido e socializado (Junqueira, Maior \& Pinheiro, 2011).

Diante do exposto, este trabalho consiste em uma análise bibliométrica (Vanti, 2002), de natureza descritiva e explicativa (Francisco, 2011). As análises da produção científica constituem objeto da bibliometria (Zhao, 2006). Boyack, Wylie e Davidson (2002) e Guedes e Borschiver (2005) propõem a utilização de métodos quantitativos para investigar a produção escrita como o elemento principal da comunicação do conhecimento, utilizando processos variados de levantamento, tratamento e apresentação de dados.

Assim, diferentes análises podem ser utilizadas, e o foco pode ser em áreas do conhecimento, instituições, autores, disciplinas etc, sendo que o objetivo é sempre mapear e avançar sobre o estado do conhecimento (Quonian et al., 2001; Vanti, 2002).

Tal análise se mostra ainda de grande valia, tanto no entendimeto quanto na análise do contexto informacional do tema em investigação, possibilitando visualizar as características da produção científica acerca do tema (Afonso et al., 2011).

Vale ressaltar que as três leis básicas da bibliometria, são: Lotka, Bradford e Zipf (Alvarado, 1984). De maneira geral, a Lei de Lotka se relaciona com a produtividade científica de autores (Nascimento et al., 2009). A Lei de Bradford contempla a produtividade de periódicos científicos. Já a Lei de Zipf evidencia a frequência de palavras (Souza \& Ribeiro, 2013).

No que tange ao índice de Lotka, ele pode ser calculada por meio da fórmula destacada na Equação 1. 


$$
a_{n}=a_{1} \times \frac{1}{n^{2}}
$$

Onde:

an corresponde ao número de autores com $\mathrm{n}$ artigos;

al corresponde ao número de autores que publicaram apenas um artigo; e

$n$ corresponde ao número de artigos;

$c$ corresponde ao coeficiente de Lotka $(\approx 2)$.

Complementando a investigação bibliométrica, também foi utilizado um monitoramento das redes de coautoria (Ramos-Rodríguez \& Ruíz-Navarro, 2004; Mello, Crubellate \& Rossoni, 2010), com o intuito de compreender as ligações e conectividades entre autores e suas respectivas IESs.

A escolha do banco de dados a ser analisado é um dos pontos-chave de análise bibliométrica, pois define o escopo da pesquisa, podendo impactar em sua validade. Neste trabalho, o escopo é investigar a produção científica brasileira da temática gestão socioambiental. Tal iniciativa possibilita conhecer a evolução desse tema, sob a perspectiva de um periódico específico da área socioambiental (Bufrem \& Prates, 2005), ou seja, a Revista de Gestão Social e Ambiental.

Diante do revelado, foi realizada a busca de todos os artigos, por meio do site da própria revista. Com isso, o universo da pesquisa foi composto por 175 artigos publicados no período 20072012, como mostra o Gráfico 1.

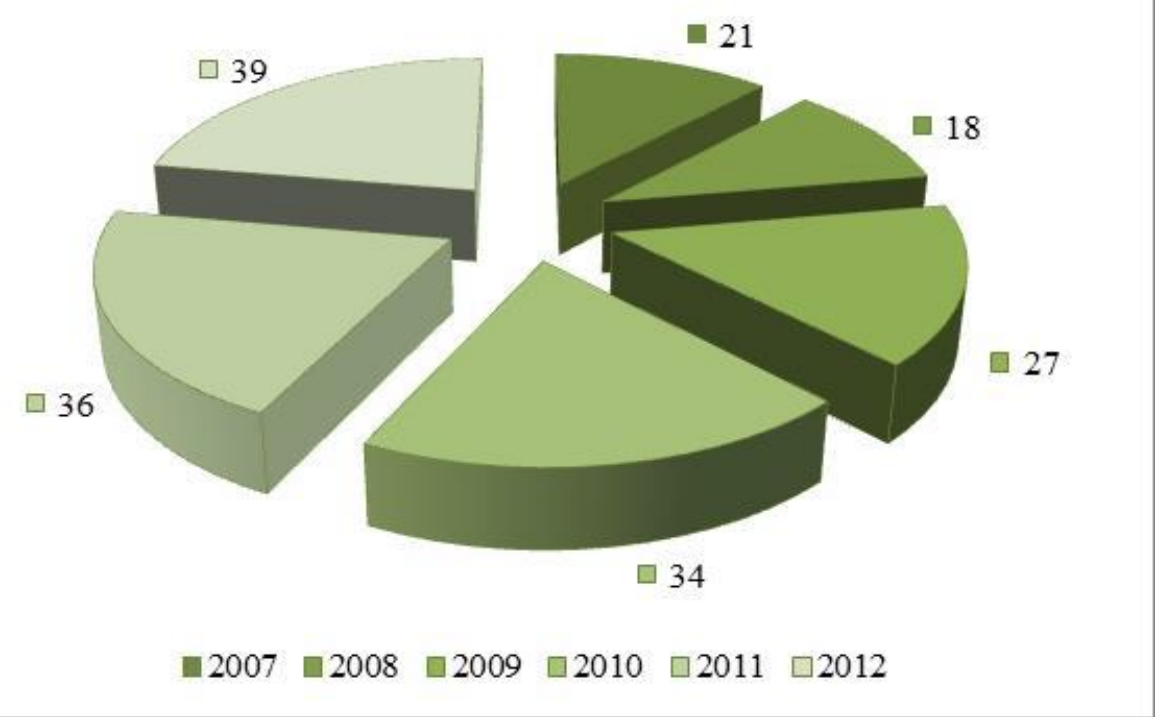

Gráfico 1 - Artigos publicados na Revista de Gestão Social e Ambiental de 2007 a 2012

Fonte: Dados da pesquisa

A análise dos indicadores: (I) número de autores por publicação; (II) autores mais prolíferos; (III) redes de coautoria; (IV) IESs mais profícuas; (V) rede das IESs; (VI) rede integrada dos autores e IES; (VII) autores e obras mais citadas; (VIII) frequência de palavras-chave; e (IX) áreas temáticas e temas abordados. Foi feita de forma quantitativa, utilizando-se estatística descritiva, por meio do uso dos softwares Ucinet 6 for Windows (versão 6.357), Wordle.net e Microsoft Excel 2007 para construir as representações gráficas utilizadas.

\section{ANÁLISE E DISCUSSÃO DOS RESULTADOS}

A finalidade deste capítulo foi mobilizar a análise bibliométrica e sociométrica dos 175 artigos publicados na Revista de Gestão Social e Ambiental. 


\subsection{Número de autores por publicação}

O Gráfico 2 apresenta a frequência de artigos de autoria individual e com dois ou mais autores por artigo no período analisado.

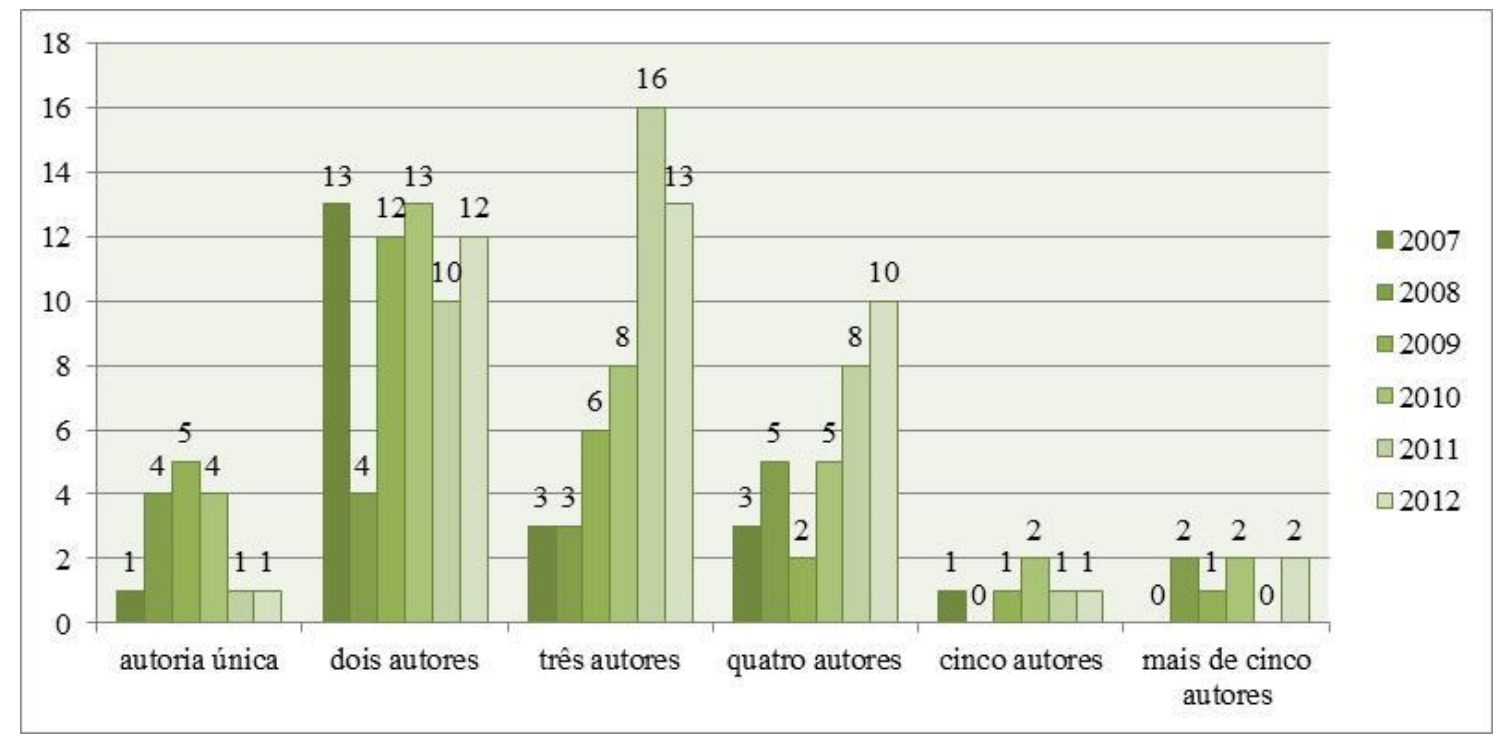

Gráfico 2 - Número de autores por publicação

Fonte: Dados da pesquisa

Pode-se notar pelo Gráfico 2 que os artigos individuais ocorrem em menor número em comparação com os demais, podendo ser um indicativo da existência de grupos de pesquisa sobre o tema gestão socioambiental. Como pode ser observado, prevalece o número de artigos publicados com dois autores, representando $36,57 \%$ da amostra.

\subsection{Autores mais prolíferos}

A análise dos autores mais prolíferos em determinado assunto revela, primeiramente, a maturidade dessa temática. Neste contexto, temas mais maduros tendem a ter pesquisadores com histórico de pesquisa relevante (Nederhof, 2006).

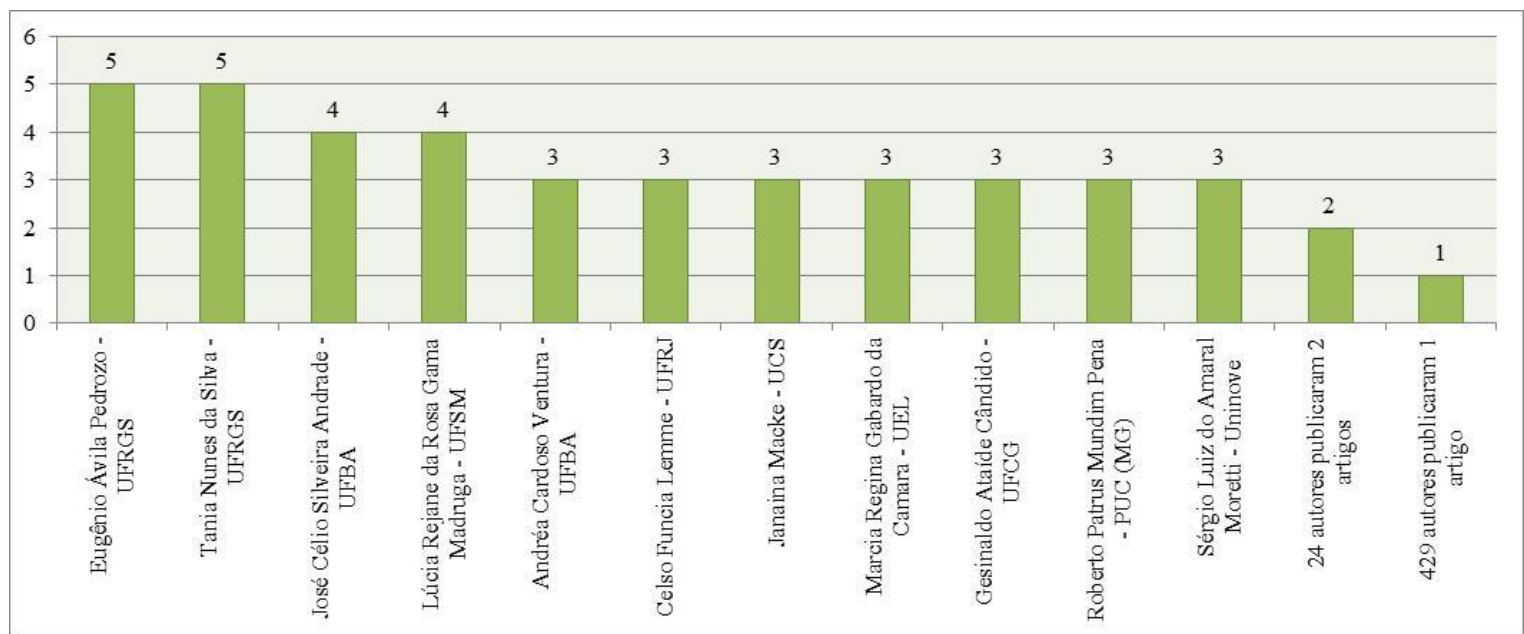

Gráfico 3 - Autores mais prolíferos

Fonte: Dados da pesquisa 
O Gráfico 3 mostra os nomes de Eugênio Ávila Pedrozo e Tania Nunes da Silva como os autores mais prolíficos que publicaram artigos sobre gestão socioambiental no período analisado, ou seja, cinco publicações, no contexto da RGSA. Em seguida, são evidenciados os autores José Célio Silveira Andrade e Lúcia Rejane da Rosa Gama Madruga, ambos com quatro artigos publicados.

Com três publicações, aparecem os articulistas: Andréa Cardoso Ventura, Celso Funcia Lemme, Janaina Macke, Marcia Regina Gabardo da Camara, Gesinaldo Ataíde Cândido, Roberto Patrus Mundim Pena e Sérgio Luiz do Amaral Moretti.

Em suma, do total dos 464 autores identificados que pertencem a 108 IESs, 11 publicaram de três a cinco artigos; 24 publicaram dois artigos e a grande maioria, ou seja, 429 pesquisadores publicaram somente um artigo em seis anos de pesquisa. Estas informações vão ao encontro da Lei de Lotka que prega a produtividade científica dos pesquisadores (Souza \& Ribeiro, 2013). Este fato remete a pesquisa dos autores Grzebieluckas, Campos e Selig (2012).

Ressalta-se que o padrão obtido por Lotka (1926) foi de 60\%, ou seja, este indicador mostra que $60 \%$ dos pesquisadores de uma determinada área do conhecimento publicam apenas uma vez (Nascimento et al., 2009), contudo, neste estudo, foi encontrado um percentual superior ao padrão encontrado por Lotka (conforme a Equação 1), isto é, um percentual aproximado de $70 \%$ de articulistas que publicaram uma vez nesta base de dados investigada.

\subsection{Redes de coautoria}

A colaboração entre autores vem sendo vista internacionalmente como um dos indicadores de qualidade da pesquisa, principalmente em temas interdisciplinares (Subramanyam, 1983), como é o caso da gestão socioambiental.

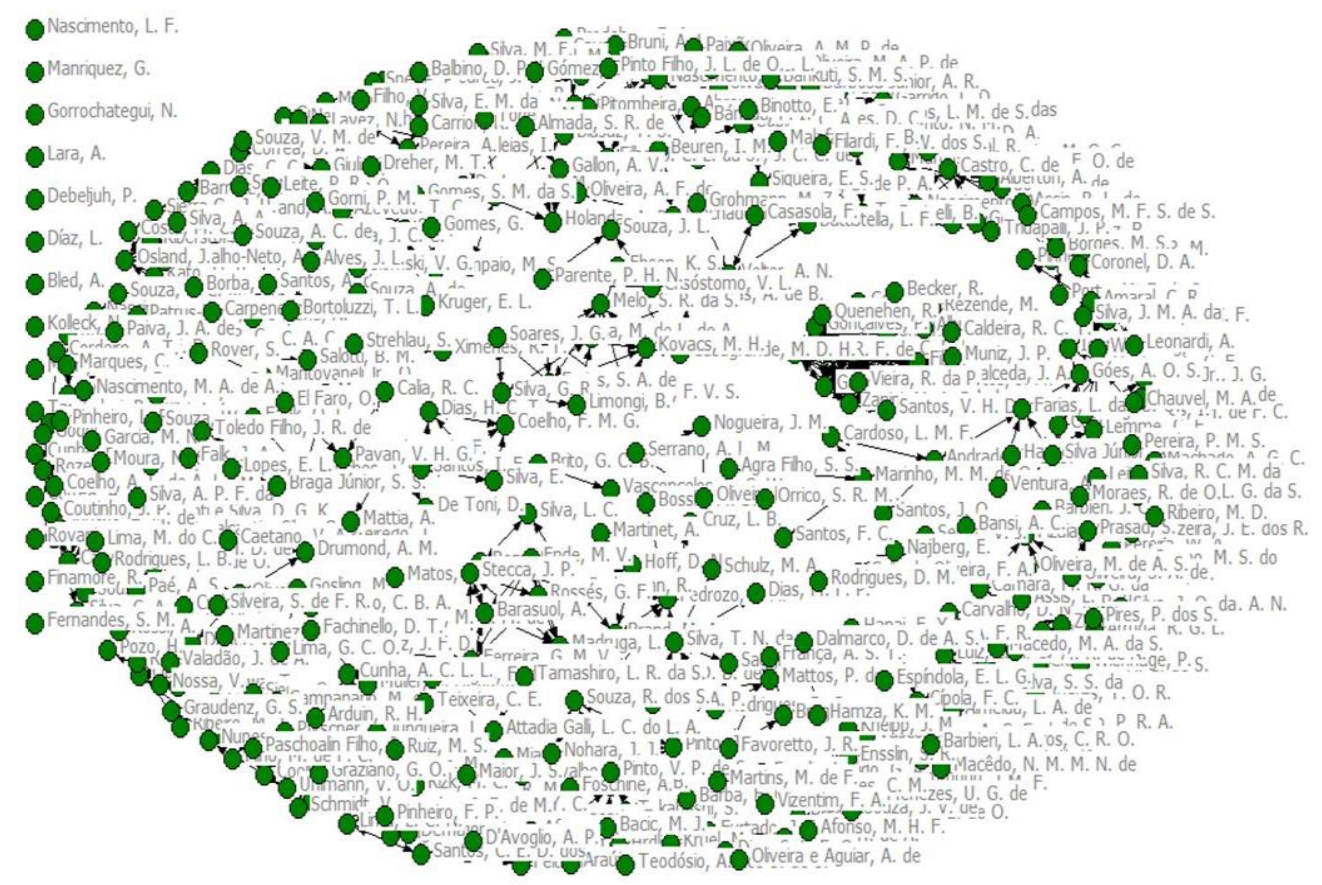

Figura 1- Redes de coautoria

Fonte: Dados da pesquisa

Ao analisar a Figura 1, constatam-se várias redes de colaboração, porém com uma densidade de 0.0077 , em que se observa uma rede de autores bem esparsa, ou seja, uma centralidade entre os autores. E isto impacta na produção acadêmica do tema ora estudado, cujas relações entre os coautores podem ser utilizadas como indicadoras de produção científica (Mello, Crubellate \& Rossoni, 2010). 


\subsection{IESs mais profícuas}

O Gráfico 4 mostra as 13 IESs que mais publicaram sobre o tema gestão socioambiental no contexto da RGSA na temporalidade de seis anos.

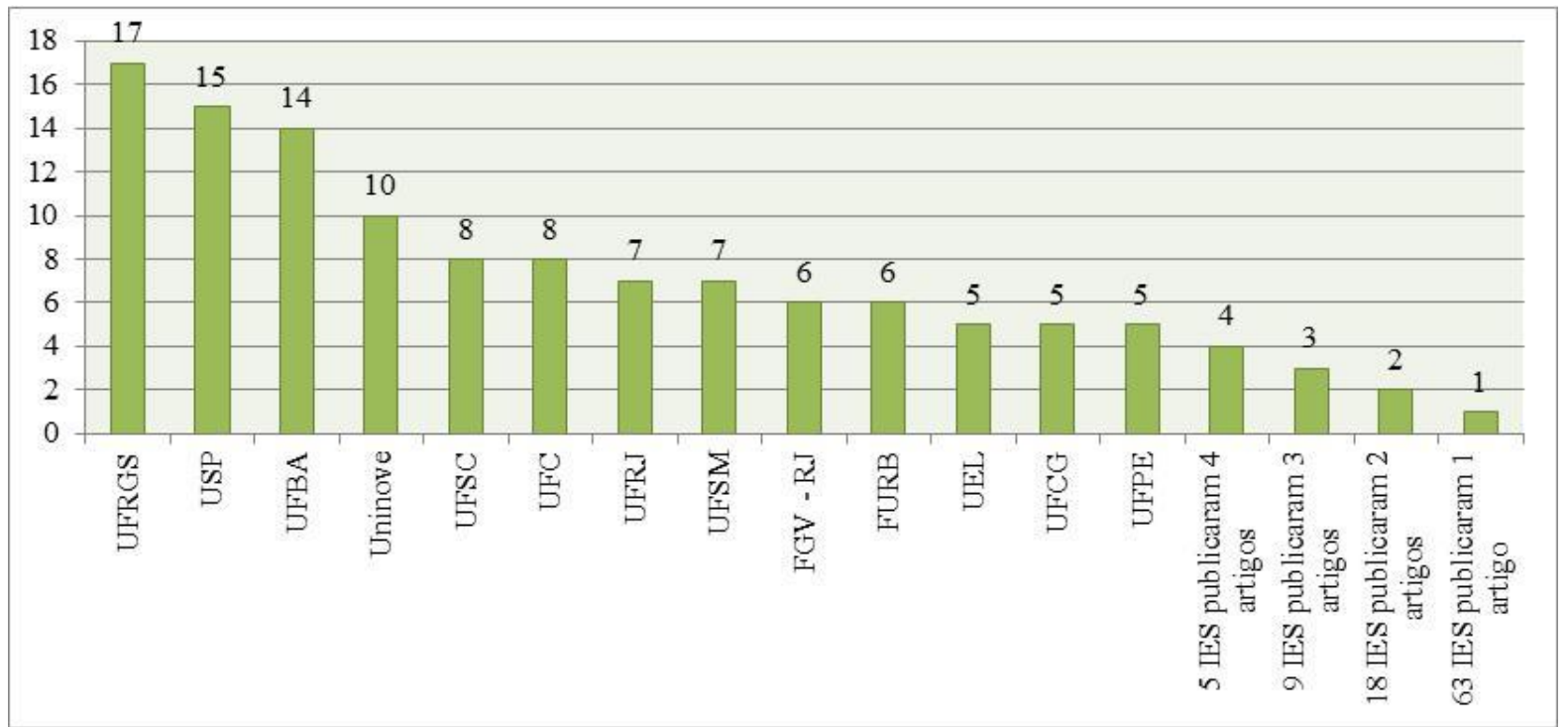

Gráfico 4 - IESs mais profícuas

Fonte: Dados da pesquisa

As IESs: UFRGS, USP, UFBA e UNINOVE são as universidades que mais produziram artigos na RGSA, ou seja, 17, 15, 14 e 10 publicações, respectivamente. Destacam-se também as seguintes IESs: UFSC e UFC, ambas com oito publicações; seguidas das instituições de ensino, UFRJ e UFSM, com sete artigos; FGV - RJ e FURB, com seis publicações; e, finalmente, as universidades: UEL, UFCG e UFPE, todas com cinco publicações.

Ainda cabe salientar que do total de 108 IESs, 13 publicaram de cinco a 17 artigos; 32, de dois a quatro artigos; e 58,33\% das IESs, apenas um artigo. Menciona-se também que destas 108 instituições, 13 são estrangeiras e publicaram juntas 15 artigos, são elas: três IESs são da Argentina; duas instituições da França; uma, da África; uma, da Alemanha; uma, do Canadá; uma, do Chile; uma, da Colômbia; uma, dos EUA; uma, de Moçambique; e uma, de Portugal. E destas, cinco IESs são da América do Sul; quatro, da Europa; duas, da América do Norte; e duas, da África.

\subsection{Rede das IESs}

A Figura 2 evidencia a rede das 108 IESs deste estudo.

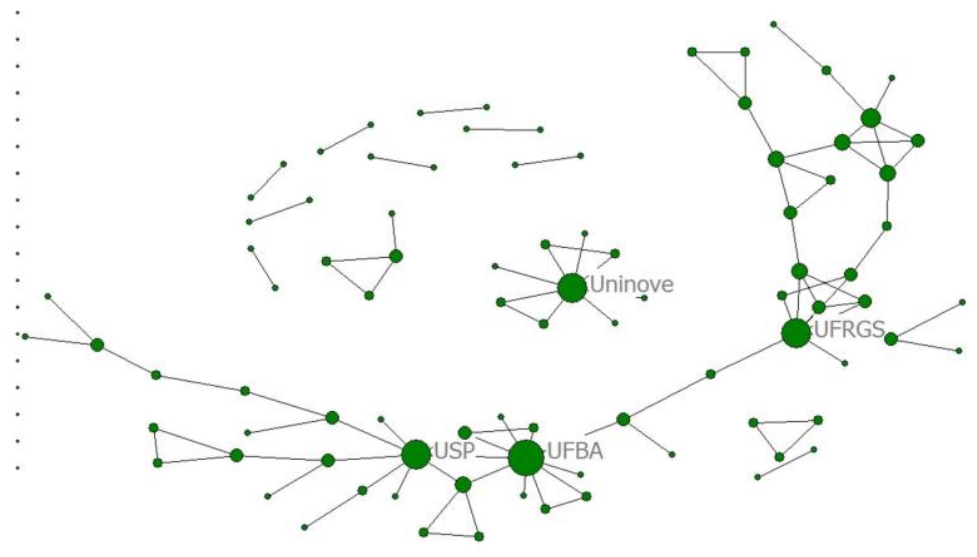

Figura 2 - Redes das IESs

Fonte: Dados da pesquisa 
Analisando a rede das IESs, destacam-se as IESs: UFBA, UFRGS, Uninove e USP, por serem as mais centrais entre as 108 instituições de ensino identificadas. Tal dado remete a uma centralidade destes grupos e, consequentemente, das quatro IESs mais prolíferas no que tange a produção de artigos sobre o tema gestão socioambiental na perspectiva da RGSA. A densidade da rede das IESs corrobora com esta informação ao descrevê-la com 0.0183 , ou seja, somente $1,83 \%$ das relações totais são trabalhadas, resultado muito aquém do ideal de uma rede de atores.

\subsection{Rede integrada dos autores e IES}

A Figura 3 apresenta as IESs e seus respectivos autores vinculados a elas.

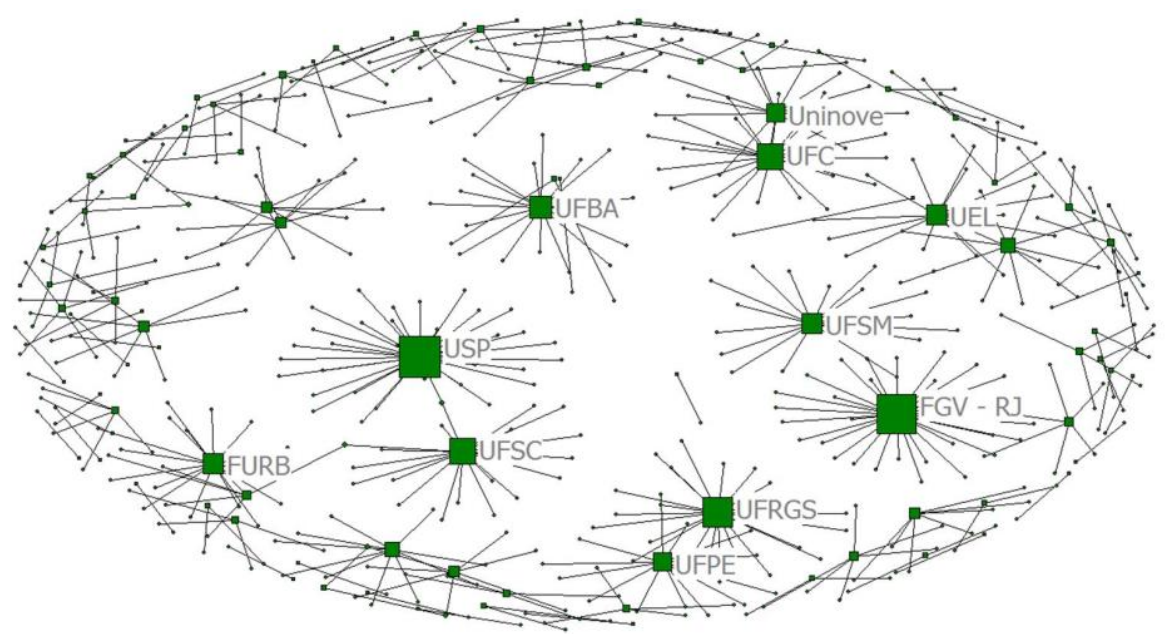

Figura 3 - Rede integrada dos autores e IESs

Fonte: Dados da pesquisa

Observa-se que as IES: FGV - RJ, USP, UFRGS, UFC, UFSC, UFBA, FURB, Uninove, UEL, UFSM e UFPE, são as que contêm, respectivamente, maior número de autores relacionados a elas. Coincidentemente, tal dado remete e confirma as informações contempladas no Gráfico 4 e na Figura 2 sobre a proficuidade destas IESs no que se refere a produção científica sobre o tema gestão socioambiental e sobre sua centralidade na rede de colaboração das instituições de ensino, sob a perspectiva da RGSA.

\subsection{Autores e suas respectivas obras mais citadas}

A figura 4 apresenta os dez autores mais citados com suas respectivas obras em 175 artigos investigados na RGSA.

\begin{tabular}{|l|}
\hline \multicolumn{1}{|c|}{ Autores e suas obras } \\
\hline Carroll, A. B. A. (1979). Three-dimensional conceptual model of corporate social performance. Academy of \\
Management Review, 4(4), 497-505. \\
\hline Barbieri, J. C. (2004). Gestão ambiental empresarial: conceitos, modelos e instrumentos. São Paulo: Saraiva. \\
\hline Sachs, I. (2002). Caminhos para o desenvolvimento sustentável. 4.ed. Rio de Janeiro: Garamond. \\
\hline Freeman, R. E. (1984). Strategic management: a stakeholder approach. Boston: Pitman. \\
\hline Gil, A.C. (1991). Como Elaborar Projetos de Pesquisa. 3 ed. São Paulo: Atlas. \\
\hline Ashley, P. A. (2002). Ética e responsabilidade social nos negócios. São Paulo: Saraiva. \\
\hline Leite, P. R. (2003). Logística reversa: meio ambiente e competitividade, São Paulo: Pearson Education Hall. \\
\hline Porter, M. E., \& Linde, C. (1995). Green and competitive: ending the stalemate. Harvard Bussines Review, \\
73(5), 120-134. \\
\hline Bardin, L. (2004) Análise de conteúdo. Lisboa: Edições 70. \\
\hline Yin, R. K. (2005). Estudos de caso: planejamento e métodos. (3a ed.). Porto Alegre: Bookman. \\
\hline
\end{tabular}

Figura 4 - Autores mais citados e suas obras

Fonte: dados da pesquisa 
Analisando o Quadro 1, verifica-se que 60\% dos autores mais citados são internacionais. Ressalta-se que $80 \%$ das citações são oriundas de livros e as únicas de periódicos, são justamente as internacionais. Gallon et al. (2008) corroboram no que tange a predominância das citações de livros.

Observa-se, também, que das 10 referências, uma é da década de 1970 (justamente a mais citada); uma é da década de 1980; duas da década de 1990; e a maioria, ou seja, seis são pertencentes a década de 2000, porém, nenhuma destas citações que mais apareceram retratam o estado da arte com pesquisas mais recentes da área.

No que tange aos autores nacionais, Barbieri, J. C. é o mais citado nos artigos publicados na RGSA. Na pesquisa de Souza e Ribeiro (2013), o referido autor, além de ser um dos mais citados na área, é também um dos que mais publicou sobre a temática ambiental em periódicos nacionais nos 20 anos de análise dos autores.

É interessante notar que das 10 obras mais citadas, três têm relação direta com métodos de pesquisa, a saber: Gil, Bardin e Yin. Esse resultado corrobora as pesquisas de Cabral, Siqueira e Siqueira-Batista (2009) que indicaram um volume grande de citações de livros desses autores na área de métodos de pesquisa.

\subsection{Frequência de palavras-chave}

A Figura 5 evidencia as palavras-chave mais frequentes nos 175 artigos da RGSA, sendo assim considerados os termos aplicados exaustivamente pelos pesquisadores em seus artigos publicados, sendo assim, não há muito coisa a acrescentar a essa constatação (Francisco, 2011).

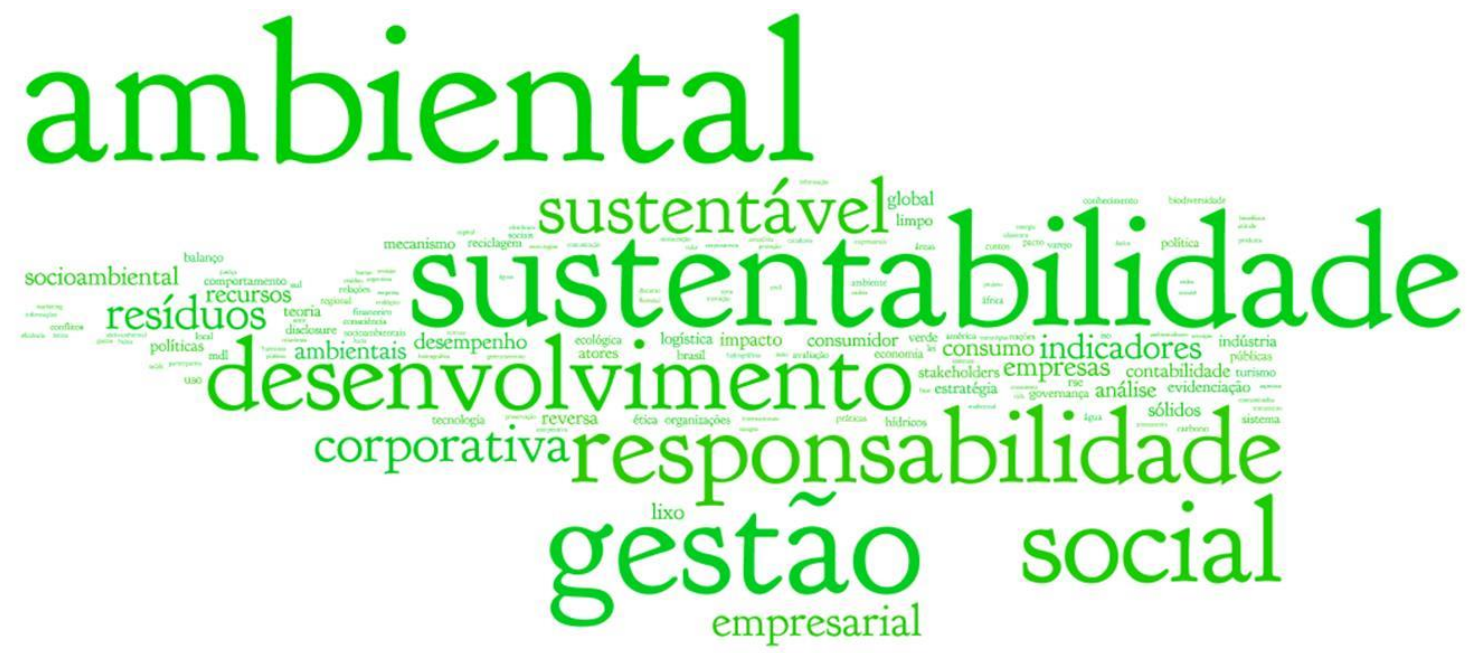

Figura 5 - Frequência das palavras-chave

Fonte: Dados da pesquisa

As palavras-chave que se destacaram foram: ambiental, sustentabilidade, gestão, social, desenvolvimento e responsabilidade, entre outras. Nota-se similaridade das palavras-chave com os principais temas abordados (Tabela 2) nos 175 artigos da RGSA.

Essas palavras-chave contemplam, de forma conjunta ou individual, o escopo dos conteúdos mais explorados, evidenciando que o aspecto social fica menos citado se comparado com o ambiental, tendo a palavra-chave socioambiental menos citada nos 175 estudos da revista RGSA. Remete a Lei de Zipf que enfatiza a frequência de palavras nos artigos (Souza \& Ribeiro, 2013).

\section{9 Áreas temáticas e temas abordados}

A análise das áreas temáticas e dos temas abordados é vista como fator preponderante para continuidade das pesquisas, proporcionando um norte para autores, o que impacta o crescimento, a disseminação e socialização das pesquisas. As Tabelas 1 e 2, mostram, respectivamente, a 
Análise da produção científica da temática gestão socioambiental na perspectiva da revista RGSA

frequência das áreas temáticas e dos temas mais abordados nos 175 artigos explorados em seis anos de estudo na RGSA.

Tabela 1 - Áreas temáticas

\begin{tabular}{lrrrrrrrr}
\hline Áreas temáticas / Anos & $\mathbf{2 0 0 7}$ & $\mathbf{2 0 0 8}$ & $\mathbf{2 0 0 9}$ & $\mathbf{2 0 1 0}$ & $\mathbf{2 0 1 1}$ & $\mathbf{2 0 1 2}$ & Total & Total \\
\hline Abordagens e práticas sustentáveis & 10 & 7 & 11 & 8 & 17 & 10 & 63 & 36,00 \\
\hline Gestão ambiental em organizações & 3 & 6 & 4 & 8 & 13 & 12 & 46 & 26,29 \\
\hline Meio ambiente e sociedade & 5 & 4 & 10 & 9 & 2 & 14 & 44 & 25,14 \\
\hline Gestão socioambiental setorial & 3 & 1 & 2 & 9 & 4 & 3 & 22 & 12,57 \\
\hline Total & $\mathbf{2 1}$ & $\mathbf{1 8}$ & $\mathbf{2 7}$ & $\mathbf{3 4}$ & $\mathbf{3 6}$ & $\mathbf{3 9}$ & $\mathbf{1 7 5}$ & $\mathbf{1 0 0 , 0 0}$ \\
\hline
\end{tabular}

Fonte: Dados da pesquisa

Entre as quatro áreas temáticas contempladas na Tabela 1, ressalta-se a área "Abordagens e Práticas Sustentáveis", pois, só ela corresponde a 36\% do total de 175 artigos analisados nesta pesquisa. Tal fato pode ser em razão da RGSA ter um número considerável de estudos de caso, que apresentam pesquisas de abordagens e práticas sustentáveis. A Tabela 2 complementa as informações da Tabela 1, descrevendo os 44 temas abordados nos seis anos de estudo.

Tabela 2 - Temas abordados

\begin{tabular}{|c|c|c|c|c|c|c|c|c|}
\hline Temas abordados & $\mathbf{0 7}$ & 08 & 09 & 10 & 11 & 12 & Total & $\%$ \\
\hline Ética e responsabilidade social & 7 & 6 & 4 & 3 & 4 & 4 & 28 & 16,00 \\
\hline Contabilidade ambiental & 2 & 1 & 1 & 3 & 3 & 4 & 14 & $\mathbf{8 , 0 0}$ \\
\hline Marketing verde & & & 1 & & 2 & 7 & 10 & $\mathbf{5 , 7 1}$ \\
\hline Gestão ambiental em setores específicos & 2 & & 2 & 3 & 2 & & 9 & 5,14 \\
\hline Indicadores de sustentabilidade & 1 & 1 & 2 & & 1 & 3 & 8 & 4,57 \\
\hline Gerenciamento integrado de resíduos sólidos & & & & 4 & 1 & 2 & 7 & $\mathbf{4 , 0 0}$ \\
\hline Gestão socioambiental e desempenho empresarial & & & 2 & 1 & 3 & & 6 & 3,43 \\
\hline Logística reversa & & & 1 & & 3 & 2 & 6 & 3,43 \\
\hline Governança ambiental & & & 5 & & & & 5 & 2,86 \\
\hline Tecnologias limpas & & 2 & 1 & 1 & & 1 & 5 & 2,86 \\
\hline Agricultura sustentável & & & & 3 & 1 & 1 & 5 & 2,86 \\
\hline Consumo sustentável & & & & 1 & 3 & & 4 & 2,29 \\
\hline Inovação sustentável & 1 & & & 1 & 2 & & 4 & 2,29 \\
\hline Parcerias interorganizacionais e empreendedorismo socioambiental & & & 2 & 2 & & & 4 & 2,29 \\
\hline Mecanismo de desenvolvimento limpo (MDL) & 3 & & & 1 & & & 4 & 2,29 \\
\hline Gestão de recursos hídricos & 1 & & 1 & 1 & 1 & & 4 & 2,29 \\
\hline Avaliação de impactos ambientais & & 1 & & & 1 & 2 & 4 & 2,29 \\
\hline Ensino e pesquisa & & & & & 3 & & 3 & 1,71 \\
\hline Sistemas de gestão ambiental & & & & 2 & 1 & & 3 & 1,71 \\
\hline Gestão ambiental em micro, pequena e média empresa & & 1 & & 2 & & & 3 & 1,71 \\
\hline Conflitos ambientais & & 1 & 1 & 1 & & & 3 & 1,71 \\
\hline Ecoeficiência & 1 & & & & 1 & 1 & 3 & 1,71 \\
\hline Gestão de resíduos sólidos & & & & 1 & 1 & 1 & 3 & 1,71 \\
\hline Evidenciação ambiental & & & & & & 3 & 3 & 1,71 \\
\hline Investimentos sustentáveis e fundos éticos & 1 & & 1 & & & & 2 & $\mathbf{1 , 1 4}$ \\
\hline Ecoturismo e turismo sustentável & & & & 1 & 1 & & 2 & $\mathbf{1 , 1 4}$ \\
\hline Comércio internacional e meio ambiente & 1 & & 1 & & & & 2 & $\mathbf{1 , 1 4}$ \\
\hline Acordos ambientais internacionais e setoriais & & 2 & & & & & 2 & $\mathbf{1 , 1 4}$ \\
\hline Estudo de impacto ambiental e licenciamento & & & & 1 & & 1 & 2 & 1,14 \\
\hline Ambientalismo & & & & & & 2 & 2 & $\mathbf{1 , 1 4}$ \\
\hline Desenvolvimento regional & & & & & & 2 & 2 & $\mathbf{1 , 1 4}$ \\
\hline Compras públicas sustentáveis & & & & & 1 & & 1 & $\mathbf{0 , 5 7}$ \\
\hline Auditoria ambiental & & & & & 1 & & 1 & $\mathbf{0 , 5 7}$ \\
\hline Ecologia industrial & & 1 & & & & & 1 & $\mathbf{0 , 5 7}$ \\
\hline Gestão de pessoas e educação ambiental corporativa & & 1 & & & & & 1 & $\mathbf{0 , 5 7}$ \\
\hline Gestão ambiental em arranjos produtivos locais & 1 & & & & & & 1 & $\mathbf{0 , 5 7}$ \\
\hline Educação ambiental & & & & 1 & & & 1 & $\mathbf{0 , 5 7}$ \\
\hline
\end{tabular}


Marco regulatório e normativo ambiental

Política pública e marco regulatório ambiental

Técnicas de avaliação e valoração econômica

Paradigmas de proteção ambiental

Estratégia

Comércio justo

Avaliação do ciclo de vida

Total

\begin{tabular}{llr}
1 & $\mathbf{0 , 5 7}$ \\
\hline
\end{tabular}

Fonte: Dados da pesquisa

Ao analisar a Tabela 2, verificou-se que os temas considerados de fronteira, ou seja, os tópicos quentes (Madruga, 2011), que se relacionam com a temática gestão social e ambiental na perspectiva da RGSA, foram: ética e responsabilidade social (aparecendo em 28 artigos), contabilidade ambiental (publicado em 14 papers), marketing verde (10 artigos), gestão ambiental em setores específicos (nove publicações), e indicadores de sustentabilidade (oito manuscritos).

Estes dados vão ao encontro, de maneira similar, dos resultados dos respectivos estudos dos autores Gallon et al. (2007), Gallon et al. (2008), Moretti e Campanario (2009), Pereira et al. (2011), Souza et al. (2011), Machado Júnior et al. (2013), Souza e Ribeiro (2013). Os temas ética e responsabilidade social tornaram-se essenciais e preponderantes para a sustentabilidade dos negócios das organizações (Ashley, 2002), influenciando, assim, no seu crescimento na literatura acadêmica nacional.

Dos 44 temas identificados nos 175 artigos, 16\% deles são estudos sobre ética e responsabilidade social, e apresentam uma inserção maior nos anos 2007 e 2008, tendo nos anos posteriores um pequeno decréscimo, mas ainda assim mantiveram o maior numero de abordagens, o que evidencia a importância deste tema.

O tema contabilidade ambiental é um ramo da contabilidade que atualmente tem gerado interesse nos âmbitos empresarial e acadêmico (Grzebieluckas, Campos \& Selig, 2012), sendo assim, considerado um tema emergente, que mostra a preocupação com a comunicação e prestação de contas envolvidas na gestão socioambiental. Os autores Rover, Santos e Salotti (2012), em sua pesquisa, evidenciaram a importância, emergência e crescimento da temática contabilidade ambiental.

$\mathrm{O}$ assunto marketing verde também ficou em destaque neste estudo, isto, em razão de ser considerado um nicho crescente no mercado, ou seja, uma tendência em um ambiente globalizado das organizações (Giuliani, 2004). Quanto a temática gestão ambiental em setores específicos, mostra a dimensão ambiental em organizações diversas, com práticas e abordagens diferenciadas.

Em relação ao tema indicadores de sustentabilidade, entende-se que ele alcançou o destaque nesta pesquisa, na perspectiva da revista RGSA, por serem considerados como informações essenciais que auxiliam os gestores na avaliação ambiental, sendo importantes também na construção de cenários no caminho rumo à sustentabilidade empresarial (Siche et al., 2007).

Já o tema gerenciamento integrado de resíduos sólidos também ostenta uma posição de destaque neste estudo, aparecendo como tema principal em sete publicações, podendo ser, em decorrência de sua importância na sociedade, decorrente da Política Nacional de Resíduos Sólidos em 2010 (Ribeiro \& Machado, 2009).

Em suma, dos 44 temas identificados neste trabalho, 31 apareceram como item principal em 31 papers; e 13 assuntos só foram publicados uma vez: compras públicas sustentáveis, auditoria ambiental, ecologia industrial, gestão de pessoas e educação ambiental corporativa, gestão ambiental em arranjos produtivos locais, educação ambiental, marco regulatório e normativo ambiental, política pública e marco regulatório ambiental, técnicas de avaliação e valoração econômica, paradigmas de proteção ambiental, estratégia, comércio justo, avaliação do ciclo de vida. Esta informação é útil, pois, além de uma oportunidade representa também sugestão para fomento destes temas em futuras publicações na RGSA. 


\section{CONSIDERAÇÕES FINAIS}

Este artigo investigou a produção científica brasileira da temática gestão socioambiental na perspectiva da Revista de Gestão Social e Ambiental, no período de 2007 a 2012. Para tanto, efetuou-se uma análise bibliométrica e sociométrica em um universo de 175 artigos. Foi priorizado na pesquisa o foco nos seguintes critérios: (I) número de autores por publicação; (II) autores mais prolíferos; (III) redes de coautoria; (IV) IESs mais profícuas; (V) rede das IESs; (VI) rede integrada dos autores e IES; (VII) autores e obras mais citadas; (VIII) frequência de palavras-chave; e (IX) áreas temáticas e temas abordados.

A análise bibliométrica como ferramenta se mostra de grande valia na compreensão e análise da área de pesquisa, no caso a RGSA, o que possibilitou visualizar a produção científica disseminada e socializada por este periódico. Este estudo revela o caráter multidisciplinar que possui a abordagem da referida revista, com temas variados ligados a sustentabilidade, abarcando questões ambientais e de dimensão social. O número destacado de estudos de caso confirmam as práticas de sustentabilidade implementadas nas organizações.

Como principal fonte de socialização, a IES mais profícua na Revista de Gestão Social e Ambiental, foi a UFRGS, sendo dessa IES os docentes considerados mais profícuos. Vale destacar que o pesquisador é a parte fundamental do processo, o que influencia e impacta diretamente a produção das Instituições de Ensino Superior.

Este estudo contribuiu de maneira macro para se compreender melhor, sob a ótica da RGSA, o tema gestão socioambiental e todas as nuances que o cercam, como, por exemplo, suas temáticas, que foi liderada pelo assunto ética e responsabilidade social, mostrando assim sua importância no contexto organizacional (Zylbersztajn, 2002). Suas redes de colaboração, que são um conjunto de relacionamentos estabelecidos entre os atores (Nascimento \& Beuren, 2011), isto é, os autores e suas respectivas IESs, ajudam a entender os grupos de relacionamento da área ambiental, à luz da revista investigada.

O fator limitador do artigo foi a quantidade de trabalhos para se analisar, o que contribui para reduzir as conclusões sobre a revista pesquisada. Outra limitação deste estudo foi a pesquisa em apenas uma revista. Entretanto, salienta-se que o objetivo deste estudo foi alcançado. É importante destacar que este estudo não pode ser dito como acabado, por existir outras formas de aprofundá-lo, por meio de estudos de redes sociais mediante a mensuração de outros indicadores, que aperfeiçoariam os resultados desta pesquisa. Ainda é possível aprofundar este estudo pela análise de conteúdo a fim de completar os resultados obtidos neste trabalho e comparar com outros estudos de revistas da área. Outra sugestão é aperfeiçoar este estudo, comparando-o com outro(s) periódico(s) da área ambiental.

\section{REFERÊNCIAS}

Afonso, M. H. F., Souza, J. V. de, Ensslin, S. R., \& Ensslin, L. (2011) Como construir conhecimento sobre o tema de pesquisa? Aplicação do processo proknow-c na busca de literatura sobre avaliação do desenvolvimento sustentável. Revista de Gestão Social e Ambiental, 5(2), 47-62.

Alvarado, R. U. (1984) A bibliometria no Brasil. Ciência da Informação, 13(2), 91-105.

Ashley, P. A. (2002) Ética e responsabilidade social nos negócios. São Paulo: Saraiva.

Barbieri, J. C. (2007) Gestão ambiental empresarial: conceitos, modelos e instrumentos. São Paulo: Saraiva.

Boyack, K. W., Wylie, B. N., \& Davidson, G. S. (2002) Domain visualization using vx insight for science and technology management. Journal of the American Society for Information Science and Technology, 53(9), 764-774. 
Borger, F. (2006) Responsabilidade corporativa: a dimensão ética, social e ambiental na gestão das organizações. In: Junior, V. A., \& Demajorovic, J. (Org.). Modelos e Ferramentas de Gestão Ambiental: desafios e perspectivas para as organizações. São Paulo: Senac.

Bordin, É. M. B. (2009) A gestão social no contexto das organizações da sociedade civil: desafios para efetivação da Cidadania. 215f. Dissertação de Mestrado em Serviço Social, PUC, Porto Alegre.

Bufrem, L., \& Prates, Y. (2005) O saber científico registrado e as práticas de mensuração da informação. Ciência da informação, 34(2), 9-25.

Cabral, I., Siqueira, J. R. M. de, \& Siqueira-Batista, R. (2009) O diálogo das ciências contábeis com as ciências humanas e demais ciências sociais: uma análise da produção acadêmica do Congresso Usp de Controladoria e Contabilidade e Enanpad. In: Associação Nacional de Pós-Graduação e Pesquisa em Administração. Anais Eletrônicos... Recuperado In: Associação Nacional de PósGraduação e Pesquisa em Administração. Anais Eletrônicos... Recuperado em: 08 ago.2012, de http://www.anpad.org.br/diversos/trabalhos/EnANPAD/enanpad_2011/EPQ/EPQ3156.pdf.

Carroll, A. B. A. (1979) Three-dimensional conceptual model of corporate social performance. Academy of Management Review, 4(4), 497-505.

Coordenação de Aperfeiçoamento de Pessoal de Nível Superior (Capes) (2012/2010) WebQualis. Recuperado de http://qualis.capes.gov.br/webqualis/

Farias, L. das G. Q., Góes, A. O. S., \& Silva Júnior, A. C. (2010) Gestão ambiental e tecnologias ambientais: práticas e benefícios em uma indústria alimentícia no sul da Bahia. Revista de Gestão Social e Ambiental, 4(1), 80-91.

Fischer, T. (2002) Poderes locais, desenvolvimento e gestão: introdução a uma agenda. In: Fischer, T. (Org.) Gestão do desenvolvimento e poderes locais: marcos teóricos e avaliação. Salvador: Casa da Qualidade.

Francisco, E. de R. (2011) RAE-eletrônica: exploração do acervo à luz da bibliometria, geoanálise e redes sociais. Revista de Administração de Empresas, 51(3), 280-306.

Gallon, A. V., Souza, F. C. de, Rover, S., \& Bellen, H. M. van. (2007) Produção científica e perspectivas teóricas da área ambiental: um levantamento a partir de artigos publicados em congressos e periódicos nacionais da área de contabilidade e administração. In: Congresso USP de Controladoria e Contabilidade. Anais Eletrônicos... Recuperado em: 08 ago.2012, de http://www.congressousp.fipecafi.org/artigos72007/118.pdf.

longitudinal da produção científica em administração.,$\quad \&$ direcionada à temática ambiental. Alcance, 15(1), 81-101.

Garriga, E., \& Melé, D. (2004) Corporate social responsibility theories: mapping the territory. Journal of Business Ethics, 53, 51-71.

Giuliani, A. C. (2004) Marketing ecológico: análise e tendências em um ambiente globalizado. Revista de Administração da Unimep, 2(1), 37-56. 
Gómez, C. R. P., \& Castillo, L. A. G. (2007) ECP-Social: uma proposta de avaliação da performance social para negócios sustentáveis. Cadernos EBAPE.BR, 5(3), 1-17.

Grzebieluckas, C., Campos, L. M. de S., e Selig, P. M. (2012) Contabilidade e custos ambientais: um levantamento da produção científica no período de 1996 a 2007. Produção, 22(2), 322-332.

Guedes, V. V., \& Borschiver, S. (2005) Bibliometria: uma ferramenta estatística para a gestão da informação e do conhecimento, em sistemas de informação, de comunicação e de avaliação científica e tecnológica. In: Encontro Nacional de Ciências da Informação. Anais Eletrônicos... Recuperado em: 08 ago.2012, de http://www.cinform.ufba.br/vi_anais/docs/VaniaLSGuedes.pdf.

Instituto Ethos. (2012) Valores, transparência e governança. Recuperado em: 08 ago. 2012, de://www3.ethos.org.br/conteudo/gestao-socialmente-responsavel/valores-transparencia-egovernanca//

Jabbour, C. J. C., \& Santos, F. C. A. (2006) Evolução da gestão ambiental na empresa: uma taxonomia integrada à gestão da produção e de recursos humanos. Gestão \& Produção, 13(3), 435448.

Junqueira, L. A. P., Maior, J. S., \& Pinheiro, F. P. (2011) Sustentabilidade: a produção científica brasileira entre os anos de 2000 e 2009. Revista de Gestão Social e Ambiental, 5(3), 36-52.

Lotka, A. J. (1926) The frequency distribution of scientific productivity. Journal of the Washington Academy of Sciences, 16(12), 317-323.

Macêdo, N. M. M. N. de, \& Cândido, G. A. (2011) Identificação das percepções de responsabilidade social empresarial: um estudo qualitativo a partir da aplicação do modelo conceitual tridimensional de performance social. Revista de Gestão Social e Ambiental, 5(1), 85108.

Machado Júnior, C., Souza, M. T. S. de, Ribeiro, H. C. M., Furlaneto, C. J., Silva, W. N. da, \& Campanario, P. M. (2013) Estudo bibliométrico da sustentabilidade ambiental: os 15 anos do Simpósio de Administração da Produção, Logística e Operações Internacionais - Simpoi. J Health Sci Inst., 31(2), 123-131.

Madruga, L. R. da R. G. (2011) A localização das publicações e a identificação de tópicos quentes em sustentabilidade: uma primeira aproximação usando o web of science. Revista de Gestão Social e Ambiental, 5(2), 34-46.

Mello, C. M. de, Crubellate, J. M., \& Rossoni, L. (2010) Dinâmica de relacionamento e prováveis respostas estratégicas de programas brasileiros de pós-graduação em administração à avaliação da Capes: proposições institucionais a partir da análise de redes de coautoria. Revista de Administração Contemporânea, 14(3), 434-457.

Melo Neto, F., \& Froes, C. (1999) Responsabilidade social e cidadania empresarial: a administração do terceiro setor. Rio de Janeiro: Qualitymark.

Moretti, S. L. do A., \& Campanario, M. de A. (2009) A produção intelectual brasileira em responsabilidade social empresarial - SER sob a ótica da bibliometria. Revista de Administração Contemporânea, 13(Edição Especial), 68-86. 
Moura, G. D. de, Fank, O. L., Sanches, J. R., \& Filho, J. R. de T. (2012) Perfil das pesquisas na área de gestão de custos ambientais e responsabilidade social do Congresso Brasileiro de Custos de 2005 a 2009. Revista de Gestão Social e Ambiental, 6(1), 161-176.

Nascimento, A. R. do, Santos, A. dos, Salotti, B., \& Múrcia, F. D. R. (2009) Disclosure social e ambiental: análise das pesquisas científicas veiculadas em periódicos de língua inglesa. Revista Contabilidade Vista \& Revista, 20(1), 15-40.

Nascimento, S. do, \& Beuren, I. M.(2011) Redes sociais na produção científica dos programas de pós-graduação de ciências contábeis do Brasil. Revista de Administração Contemporânea, 15(1), 47-66.

Nederhof, A. J. (2006) Bibliometric monitoring of research performance in the social sciences and the humanities: a review. Scientometrics, 66(1), 81-100.

Pacheco, A. S. V., Silva, K. V., Neto, L. M., \& Michels, E. (2013) A gestão social como alternativa gerencial em organizações do terceiro setor: o caso da associação dos amigos do hospital universitário. NAU Social, 3(5), 47-55.

Paula, S. L. de, Oliveira, A. M. P. de, \& Oliveira, M. A. P. de. (2010) Da coleta seletiva à reciclagem - o uso da comunicação interna para a implantação de um programa de gestão ambiental empresarial: um estudo de caso. Revista de Gestão Social e Ambiental, 4(2), 40-55.

Pereira, G. M. de C., Yen-Tsang, C., Manzini, R. B., \& Almeida, N. V. (2011) Sustentabilidade socioambiental: um estudo bibliométrico da evolução do conceito na área de gestão de operações. Produção, 21(4), 610-619.

Pereira, W. A., \& Campos Filho, L. A. N. (2007) Investigação sobre as semelhanças entre os modelos conceituais da responsabilidade social corporativa. Revista de Gestão Social e Ambiental, 1(1), 3-18.

Porter, M. E., \& Linde, C. (1995) Green and competitive: ending the stalemate. Harvard Bussines Review, 73(5), 120-134.

Quonian, L., Tarapanoff, K., Araújo, R. H., Jr., \& Alvares, L. (2001) Inteligência obtida pela aplicação de data mining em base de teses francesas sobre o Brasil. Ciência da Informação, 30(2), 20-28.

Ramos-Rodríguez, A. R., \& Ruíz-Navarro, J. (2004) Changes in the intellectual structure of strategic management research: a bibliometric study of the strategic management journal, 19802000. Strategic Management Journal, 25, 981-1004.

Reis, C. N. dos. (2007) A responsabilidade social das empresas: o contexto brasileiro em face da ação consciente ou do modernismo do mercado? Revista de Economia Contemporânea, 11(2), 279305.

Revista de Gestão Social e Ambiental. (2012) Edições anteriores. Recuperado em: 08 ago. 2012, de http://www.revistargsa.org/rgsa/issue/archive

Revista de Gestão Social e Ambiental. (2012). Sobre a revista. Recuperado em: 08 ago. 2012, de http://www.revistargsa.org/rgsa/about. 
Ribeiro, L. M. P., \& Machado, R. T. M.(2009) A importância da logística na gestão de resíduos sólidos em um pequeno município mineiro: decisões estratégicas no processo de transporte e roteirização. Revista de Administração da Unimep, 7(2), 118-137.

Rodriguez, C. L., Diniz, E. H., \& Ferrer, F. (2007) Influência governamental e estratégias institucionais na difusão de inovações em economias emergentes. Revista de Administração de Empresas, 47(1), 10-21.

Rover, S., Santos, A. dos, \& Salotti, B. M. (2012) Análise das pesquisas empíricas de contabilidade ambiental publicadas em periódicos nacionais e internacionais no período de 1992 a 2009. Revista de Gestão Social e Ambiental, 6(1), 143-160.

Sachs, I. (2002) Caminhos para o desenvolvimento sustentável. (4.ed.) Rio de Janeiro: Garamond.

Saggin, K. D., Rodrigues, R. G., Célia, A. P., Mattos, P. de, \& Silva, T. N. da. (2010) Gestão Ambiental nas organizações da Quarta Colônia. Revista de Gestão Social e Ambiental, 4(1), 214227.

Sehnem, S., Oliveira, M. de A. S., Ferreira, E., \& Rossetto, A. M. (2012) Gestão e estratégia ambiental: um estudo bibliométrico sobre o interesse do tema nos periódicos acadêmicos brasileiros. Revista Eletrônica de Administração, 72(2), 468-493.

Siche, R., Agostinho, F., Ortega, E., \& Romeiro, A. (2007) Índices versus indicadores: precisões conceituais na discussão da sustentabilidade de países. Ambiente \& Sociedade, 10(2), 137-148.

Souza, M. P. de. (2000). Instrumentos de gestão ambiental: fundamentos e prática. São Carlos: Riani Costa.

Souza, M. T. S. de, Machado Júnior, C., Parisotto, I. R. dos S., \& Silva, H. E. M. da. (2011). A pósgraduação stricto sensu em administração como elemento de formação de pesquisadores na área ambiental. In: Associação Nacional de Pós-Graduação e Pesquisa em Administração. Anais $\begin{array}{llllll}\text { Eletrônicos... } & \text { Recuperado } & \text { em: } & \text { ago. } & 2012, & \text { de }\end{array}$ http://www.anpad.org.br/diversos/trabalhos/EnANPAD/enanpad_2011/EPQ/EPQ3156.pdf.

, \& Ribeiro, H. C. M. (2013) Sustentabilidade ambiental: uma meta-análise da produção brasileira em periódicos de administração. Revista de Administração Contemporânea, 17(3), 368-396.

Subramanyam, K. (1983) Bibliometric studies of research collaboration: A review. Journal of information Science, 6(1), 33-38.

Tódero, M., Macke, J., \& Biasuz, T. S. (2011) O consumo consciente e sua relação com as ações de responsabilidade social empresarial. Revista de Gestão Social e Ambiental, 5(1), 158-175.

Trierweiller, A. C., Campos, L. M. de S., Carvalho, D. N. de, Santos, T. H. S. dos, Bornia, A. C., \& Peixe, B. C. S. (2012) Gestão ambiental: levantamento da produção científica brasileira em periódicos de engenharia de produção. Produção, 1-16. 
Vanti, N. A. P. (2002) Da bibliometria à webometria: uma exploração conceitual dos mecanismos utilizados para medir o registro da informação e a difusão do conhecimento. Ciência da Informação, 31(2), 152-162.

Zhao, L. (2006) How library used e-resources: an analysis of citation in CCQ. Cataloging and Classification Quarterly, 42(1), 117-131.

Zylbersztajn, D. (2000) A organização ética: um ensaio sobre as relações entre ambiente econômico e o comportamento das organizações. Texto base de aula de erudição para obtenção do título de professor titular. FEA, Universidade de São Paulo (USP), São Paulo.

(2002) Organização ética: um ensaio sobre comportamento e estrutura das organizações. Revista de Administração Contemporânea, 6(2), 123-143.

Data da submissão: 05/12/2012

Data da publicação: 30/08/2013 